\title{
Clinical Profile and Outcome of COVID 19 Patients at Tertiary Cardiovascular Center of Nepal.
}

\author{
Kunjang Sherpa ${ }^{1}$, Reeju Manandhar ${ }^{1}$, Chandra Mani Adhikari ${ }^{1}$, Murari Dhungana ${ }^{1}$, Dipanker \\ Prajapati ${ }^{1}$, Roshan Raut ${ }^{1}$, Kiran Acharya ${ }^{1}$, Amrit Bogati ${ }^{1}$, Battu Kumar Shrestha ${ }^{2}$, Surakshya Joshi ${ }^{1}$, \\ Prashant Bajracharya ${ }^{1}$, Prati Badan Dangol ${ }^{3}$, Puspa Marasaini ${ }^{3}$, Sujeeb Rajbhandari'.
}

${ }^{1}$ Department of Cardiology, Shahid Gangalal National Heart Centre.

${ }^{2}$ Department of Anesthesiology, Shahid Gangalal National Heart Centre.

${ }^{3}$ Department of Nursing, Shahid Gangalal National Heart Centre.

\section{Corresponding Author:}

Kunjang Sherpa

Shahid Gangalal National Heart Centre, Nepal.

E-mail: sherpakunjang7@gmail.com

ORCID ID NO: 0000-0003-1136-6983

Cite this article as: Sherpa K, Manandhar R, Adhikari C et al. Clinical Profile and Outcome of COVID 19 Patients at Tertiary Cardiovascular Center of Nepal. Nepalese Heart Journal 2021; Vol 18 (1): 7-11.

Submitted date: $13^{\text {th }}$ February 2021

Accepted date: $12^{\text {th }}$ April 2021

\section{Abstract}

Background and Aims: Cardiovascular comorbidities are common in patients with COVID-19 and these patients are at higher risk of morbidity and mortality. It is not known if the presence of cardiovascular co-morbid conditions poses independent risk or whether this is mediated by other factors.

Methods: This is a retrospective follow up study done at Shahid Gangalal National Heart Centre (SGNHC). The main objective of this study was to study the clinical profile, baseline comorbidities, and outcome of cardiac patients and health care worker diagnosed with COVID 19. This study retrospectively evaluated case records of all cardiovascular disease (CVD) patients admitted at SGNHC with COVID 19 cases from $1^{\text {st }}$ case diagnosed on July at SGNHC till September 2020.

Results: During this study period, 90 patients with COVID 19 with cardiovascular disease were admitted. The mean age of the study population was $52.3 \pm 19$ years with $65.6 \%$ being male. Among the study population $52(57.8 \%)$ had past history of cardiovascular disease, hypertension in $18(20 \%)$ cases, diabetes in $8(8.9 \%)$ cases. Among the patients with cardiovascular diagnosis, acute coronary syndrome was most common cardiovascular diagnosis in $23(25.6 \%$ cases) followed by rheumatic heart disease in 21 (23.4\%) cases, dilated cardiomyopathy in 7 (7.8\% cases), ischemic cardiomyopathy with reduced ejection fraction $(\mathrm{EF})$ in $7(7.8 \%)$ cases, post coronary artery bypass graft (CABG) in $8(8.9 \%)$, post valve replacement in $5(5.5 \%)$, congenital heart disease in $3.3 \%$ cases and complete heart block in $3.3 \%$ cases. Most of the cases were symptomatic with moderate illness in $46.7 \%$ cases, mild illness in $41.4 \%$ cases and severe/critical illness in $11.1 \%$ cases. Among COVID patients with cardiovascular disease, the mortality was $11.1 \%$. Conclusion: Patients with cardiovascular disease with COVID 19 have more severe COVID 19 symptoms and has higher COVID 19 related death, so strict vigilance and early intervention is needed to improve its outcome.

Keywords: COVID 19; Nepal.

DOI: https://orcid.org/10.3126/njh.v18i1.36769

\section{Introduction}

A new respiratory tract infecting agent emerged in Wuhan city of China on December 2019 which was subsequently traced to be a novel corona virus outbreak on December 31, 2019. ${ }^{1}$ World Health Organization (WHO) gave the authorized name COVID-19 for this disease caused by SARS-Cov2, a novel virus genetically related to the coronavirus responsible for the 2003 SARS outbreak and in March 11, 2020 COVID-19 was declared a global health pandemic. ${ }^{2,3}$

Cardiovascular comorbidities are common in patients with COVID-19 and these patients are at higher risk of morbidity and mortality. It is not known if the presence of cardiovascular comorbid conditions pose independent risk or whether this is mediated by other factors.

@ Nepalese Heart Journal. Nepalese Heart Journal retain copyright and works is simultaneously licensed under Creative Commons Attribution License CC - By 4.0 that allows others to share the work with an acknowledge of the work's authorship and initial publication in this journal 
Meta-analysis of 6 different studies on COVID-19 done in china showed that the proportions of hypertension, cardiovascular disease, and diabetes in patients with COVID-19 were $17.1 \%, 16.4 \%$, and 9.7\% respectively. ${ }^{4}$ Prevalence of comorbidities among individuals with COVID-19: A rapid review of current literature showed hypertension followed by diabetes and cardiovascular diseases were the most common comorbidity seen in COVID-19 positive patients across major epicenters world-wide. Although having one or more comorbidity is linked to increased disease severity, no clear association was found between having these risk factors and increased risk of fatality. ${ }^{5}$

In Nepal, the first case was reported on 23 January 2020, a 32year old Nepali man returning from Wuhan. ${ }^{6}$ Recently the outbreak of COVID-19 has created a nuisance in the health care system throughout the world and in our country too. Limited information has been available to describe the presenting characteristics and outcomes of cardiovascular patients requiring hospitalization with this illness.

This study focus to study the clinical Profile, baseline comorbidities, and outcomes of the hospitalized patients and health care worker with COVID-19 in a tertiary cardiovascular center of Nepal at the initial stage of COVID pandemic in our country.

\section{Methodology}

This is a retrospective follow up study done at Shahid Gangalal National Heart Centre (SGNHC). The main objective of this study was to study the clinical profile, baseline comorbidities, and outcome of cardiac patients diagnosed with COVID 19. This study retrospectively evaluated case records of all cardiovascular disease (CVD) patients admitted at SGNHC with COVID 19 cases from $1^{\text {st }}$ case diagnosed on July at SGNHC till September 2020. Formal approval was taken from Institutional review board of SGNHC.

The baseline data, age, sex, clinical severity of COVID, comorbidities, risk factor and outcome (recovered/mortality) were collected in preformed performa. For the outcome evaluation of the patient the hospital data were evaluated and in case of referred patient either the dedicated COVID hospital where patient was referred or the patient/patient party were contacted through telephone.

The study included all cardiovascular patients who were tested positive with RT PCR positive for SARS-CoV-2 before hospital admission. The study excluded the patient who were recovered from COVID 19 and who had persistently positive COVID 19 PCR test.

Clinical severity of COVID 19 were defined as per National Institute Of Health Covid 19 treatment guidelines for classification of COVID 19 cases:

1. Asymptomatic or Pre-symptomatic Infection: Individuals who test positive for SARS-CoV-2 by virologic testing using a molecular diagnostic (e.g., polymerase chain reaction) or antigen test, but have no symptoms. 2. Mild Illness: Individuals who have any of the various signs and symptoms of COVID 19 (e.g., fever, cough, sore throat, malaise, headache, muscle pain) without shortness of breath, dyspnea, or abnormal chest imaging 3. Moderate Illness: Individuals who have evidence of lower respiratory disease by clinical assessment or imaging and a saturation of oxygen ( $\mathrm{SpO} 2)$ $\geq 94 \%$ on room air at sea level. 4. Severe Illness: Individuals who have respiratory frequency $>30$ breaths per minute, $\mathrm{SpO} 2<94 \%$ on room air at sea level, ratio of arterial partial pressure of oxygen to fraction of inspired oxygen $(\mathrm{PaO} 2 / \mathrm{FiO} 2)<300$ or lung infiltrates $>50 \%$. 5. Critical Illness: Individuals who have respiratory failure, septic shock, and/or multiple organ dysfunctions. Comorbidities/risk factor and cardiovascular disease diagnosis based on documentation on the medical record data.

Data were entered into an electronic spread sheet (Microsoft Excel, Redmond) and the statistical analysis was done using the SPSS version 20 software. All parametric values were expressed as mean \& nonparametric values were expressed in percentage (\%).

\section{Results \\ Covid 19 Patients with Cardiovascular Disease Baseline Characterstics}

During this study period, 90 patients with COVID 19 with Cardiovascular disease were admitted. The mean age of the study population was $52.3 \pm 19$ years with $65.6 \%$ being male. Among the study population, $52(57.8 \%)$ had past history of cardiovascular disease, hypertension in $18(20 \%)$ cases, Diabetes in $8(8.9 \%)$ cases as shown in Table. 1.

Table 1: Baseline clinical characteristics of COVID 19 patients with cardiovascular diseases.

\begin{tabular}{ll|}
\hline Variable & Frequency \\
\hline Age $($ Mean $\pm \mathrm{SD})$ & $52.3 \pm 19$ \\
\hline Sex $(\mathrm{N} / \%)$ & \\
\hline Male & $59(65.6 \%)$ \\
Female & $31(34.4 \%)$ \\
\hline $\begin{array}{l}\text { Past History of Cardiovascular Disease } \\
\text { (N/\%) }\end{array}$ & $52(57.8 \%)$ \\
\hline Smoking & $28(31.1 \%)$ \\
\hline HTN & $18(20 \%)$ \\
\hline Diabetes Mellitus $(\mathrm{N} / \%)$ & $8(8.9 \%)$ \\
\hline COPD & $2(2.2 \%)$ \\
\hline
\end{tabular}

Among the patients with cardiovascular diagnosis, acute coronary syndrome was the most common cardiovascular diagnosis in 23 ( $25.6 \%$ cases) followed by rheumatic heart disease in 21 (23.4\%) cases, dilated cardiomyopathy in 7 (7.8\% cases), ischemic cardiomyopathy with reduced ejection fraction (EF) in $7(7.8 \%)$ cases, post Coronary Artery Bypass Graft (CABG) in $8(8.9 \%)$, post valve replacement in 5 (5.5\%), congenital heart disease in 3.3\% cases, complete heart block in $3.3 \%$ cases and other cases as shown in Table 2. 
Table 2: Cardiovascular disease diagnosis of COVID 19 patients.

\begin{tabular}{|c|c|c|c|}
\hline \multirow{2}{*}{$\begin{array}{l}\text { Cardiovascular } \\
\text { Disease }\end{array}$} & \multirow{2}{*}{$\begin{array}{l}N=90 \\
(100 \%)\end{array}$} & \multicolumn{2}{|c|}{ Outcome (Number) } \\
\hline & & Recovered & Expired \\
\hline $\begin{array}{l}\text { Acute Coronary } \\
\text { Syndrome }\end{array}$ & $23(25.6 \%)$ & & \\
\hline Acute Anterior Wall Myocardial Infarction (MI) & 6 & 22 & 1 \\
\hline Acute Inferior Wall MI & 3 & & \\
\hline Non ST-Elevation Myocardial Infarction (NSTEMI) & 6 & & \\
\hline Unstable Angina & 8 & & \\
\hline Rheumatic Heart Disease & $21(23.4 \%)$ & 18 & 3 \\
\hline Severe Mitral Stenosis (MS) & 12 & & \\
\hline Severe Mitral Regurgitation (MR) & 6 & & \\
\hline Severe Aortic Stenosis (AS) & 2 & & \\
\hline Severe Aortic Regurgitation (AR) & 1 & & \\
\hline Dilated Cardiomyopathy & $7(7.8 \%)$ & 6 & 1 \\
\hline $\begin{array}{l}\text { Ischemic Cardiomyopathy with Reduced Ejection } \\
\text { Fraction (EF) }\end{array}$ & $7(7.8 \%)$ & 4 & 3 \\
\hline POST CABG & $8(8.9 \%)$ & 6 & 2 \\
\hline Post Valve Replacement & $5(5 . \%)$ & 5 & \\
\hline POST Mitral Valve Replacement (MVR) & 1 & & \\
\hline POST Double Valve Replacement (DVR) & 3 & & \\
\hline POST Aortic Valve Replacement (AVR) & 1 & & \\
\hline Congenital Heart Disease & $3(3.3 \%)$ & 3 & \\
\hline Tetralogy of Fallot (TOF) & 1 & & \\
\hline Total Anomalous Pulmonary Venous Connection (TAPVC) & 1 & & \\
\hline Atrial Septal Defect (ASD) & 1 & & \\
\hline Complete Heart Block & $3(3.3 \%)$ & 3 & \\
\hline Coronary Artery Disease-Triple Vessel Disease & $3(3.3 \%)$ & 3 & \\
\hline Pericardial Effusion & $2(2.2 \%)$ & 2 & \\
\hline Hypertensive Emergency & $2(2.2 \%)$ & 2 & \\
\hline Degerative Valvular Heart Disease (VHD) & $2(2.2 \%)$ & 2 & \\
\hline Deep Vein Thrombosis & $1(1.1 \%)$ & 1 & \\
\hline Pulmonary Embolism & $1(1.1 \%)$ & 1 & \\
\hline Left Atrium (LA) Myxoma & $1(1.1 \%)$ & 1 & \\
\hline Right Ventricle (RV) Cardiomyopathy & $1(1.1 \%)$ & 1 & \\
\hline
\end{tabular}


Most of the cases were symptomatic with moderate symptoms in $46.7 \%$ cases, mild in $41.4 \%$ cases and severe/ critical in $11.1 \%$ cases as shown in figure 1. Among COVID patients with cardiovascular disease the mortality was found in $11.1 \%$ case as shown in figure 2 .

Figure 1: Clinical severity of COVID 19 patients with cardiovascular disease.

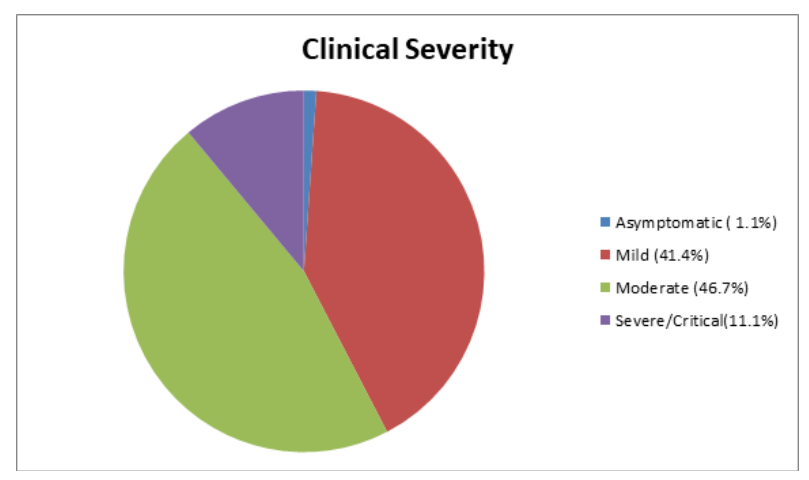

Figure 2: Outcome of COVID 19 patients with cardiovascular disease.

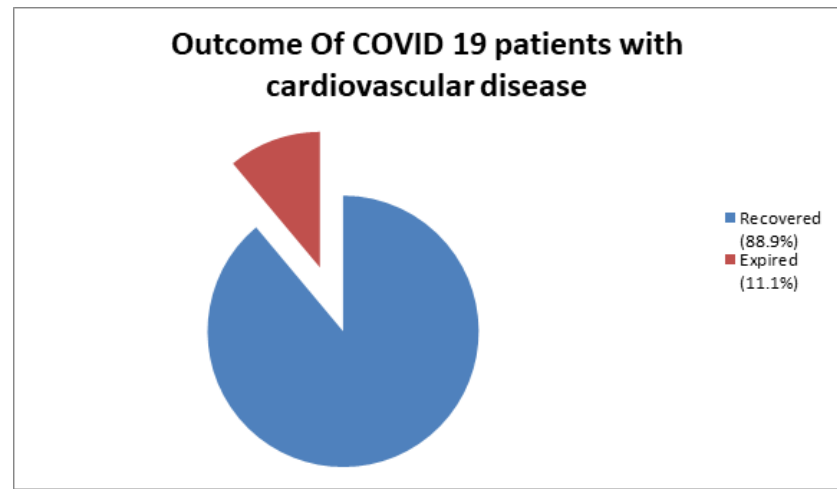

\section{Discussion}

This retrospective study done at tertiary cardiac centre in Nepal enrolled patient with cardiovascular disease with COVID positive in which $57.8 \%$ had previously diagnosed CVD, $42.2 \%$ were diagnosed as new CVD during the hospital admission. Majority of the patients with cardiovascular disease were symptomatic with $46.7 \%$ having moderate illness and $11.1 \%$ having severe/critical illnes similar to recent systematic review and meta-analysis by Kunihiro Matsushita et al which suggest that hypertension, diabetes, and CVD are independently associated with severe COVID-19.?

Our study showed the mortality during this study period among the cardiovascular patients were high and mortality rate is $11.1 \%$. The study done in various part of the world and including the meta-anylsis showed higher mortality among patients with cardiovascular disease. In recent meta-analysis, cardiovascular symptoms or complications were registered in a considerable proportion (14.1\%) of hospitalized COVID-19 patients and the case fatality rate was $9.6 \%{ }^{8}$

The study done in Nepal assessing the clinical and epidemiological features of COVID-19 deaths in Nepal found that $61 \%$ of the deaths were associated with co-morbidities where cardiovascular diseases and diabetes in $31.2 \%$ cases $^{9}$ similar to those reported in the other studies. $^{10-12}$
In another recent meta-analysis evaluating the mortality associated with cardiovascular disease in patients with COVID-19, patients with CVD and COVID-19 have a 4-fold higher risk of death. Diabetes and hypertension are also associated with higher mortality risk. Their study showed patients with CVD COVID-19 has higher mortality rate $24.2 \%$ and mortality rates were also higher in hospital registries (48.7\%) compared to national reports $(23.1 \%){ }^{13}$

The mean age of study population was $52.3 \pm 19$ years with $65.6 \%$ male patients similar to the others studies, indicating that COVID-19 commonly infects middle-aged and older population similar to the other studies done in various parts of the world in the early era of pandemic. ${ }^{14 \text { to } 17}$

Our study showed that patients with CVD, older age and comorbidities have more severe covid symptoms and has higher COVID-19 related death compared to patients without CVD similar to the study done in China which showed CVD are independent risk factors for COVID-19 patient and COVID-19 patients with CVD were more severe and had higher mortality rate.

The major limitation of the study is it was retrospective single centre study, we could not compare the mortality difference between COVID-19 positive patients with and without cardiovascular diseases. We also couldn't assess the symptoms exacerbation whether it was due to COVID-19 or due to cardiovascular disease itself. A prospective study addressing the above issue may enlighten on the mortality difference between COVID-19 positive patients with and without cardiovascular diseases.

\section{Conclusion}

Although it was a single centre retrospective study, our study conducted at the beginning of COVID-19 pandemic including cohort of patients with cardiovascular disease with COVID-19 at the tertiary referral cardiac centre have highlighted the profile and outcome of COVID-19 patients with CVD and recommends that COVID-19 patients with CVD have more severe illness, and higher COVID-19 related deaths, so early intervention and vigilance should be taken.

\section{Acknowledgement}

The author acknowledges all the healthcare and supporting staffs of SGNHC who were dedicated to serve their duty during the COVID pandemic era.

\section{Conflict of Interest: None}

\section{References}

1. Hui DS, I Azhar E, Madani TA, et al. The continuing 2019$\mathrm{nCoV}$ epidemic threat of novel coronaviruses to global health - The latest 2019 novel coronavirus out breakin Wuhan, China. Int J Infect Dis. 2020; 91:264-266. https://doi.org/10.1016/j.ijid.2020.01.009

2. Harapan H, Itoh N, Yufika A, et al. Coronavirus disease 2019 (COVID-19): A literaturere view. J Infect Public Health. 2020;13(5):667-673. https://doi.org/10.1016/j.jiph.2020.03.019

3. WHO. Novel Coronavirus-2020. Accessed 3 April 2020. https://www.who.int/csr/don/12-january-2020novelcoronavirus-china/en/

4. Li, B, Yang, J, Zhao, F. et al. Prevalence and impact of 
cardiovascular metabolic diseases on COVID-19 in China. Clin Res Cardiol 2020;109:531-538.

https://doi.org/10.1007/s00392-020-01626-9

5. Thapa Bajgain K, Badal S, Bajgain BB et al. Prevalence of comorbidities among individuals with COVID-19: A rapid review of current literature ; American Journal of Infection Control2020.06.213.

https://doi.org/10.1016/j.ajic.2020.06.213

6. Bastola A, Sah R, Rodriguez-Morales AJ, et al. The first 2019 novel coronavirus case in Nepal. Lancet Infect Dis. 2020 Mar 1;20(3):279-80.

https://doi.org/10.1016/S1473-3099(20)30067-0

7. Kunihiro M, Ning D, Minghao K, et al. The Relationship of COVID-19 Severity with Cardiovascular Disease and Its Traditional Risk Factors: A Systematic Review and MetaAnalysis Glob Heart. 2020; 15(1): 6 ; 2020 Sep 22.

PMCID: PMC7546112.

https://doi.org/10.5334/gh.814

8. Jolanda S, Salvatore RD, Giovanni SD, et al. Impact of cardiovascular risk profile on COVID-19 outcome. Ametaanalysis:PLoS One. 2020; 15(12): e0243471. 2020 Aug 14. PMCID: PMC7428172.

https://doi.org/10.1371/journal.pone.0243471

9. Panthee B, Dhungana S, Panthee N, et al. Clinical and epidemiological features of COVID-19 deaths in Nepal. New Microbe and New Infect 2020; 38: 100797. https://doi.org/10.1016/j.nmni.2020.100797

10. De Souza WM, Buss LF, Candido DDS, et al. Epidemiological and clinical characteristics of the COVID-19 epidemic in Brazil. Nat Hum Behav2020;4:856-65.

11. Stokes EK, Zambrano LD, Anderson KN, et al. Coronavirus disease 2019 case surveillance-United States, January 22-may 30, 2020. MMWR 2020;69:759-65.

https://doi.org/10.15585/mmwr.mm6924e2

12. SARS-CoV-2 Surveillance Group. Characteristics of SARS$\mathrm{CoV}-2$ patients dying in Italy. Report based on available data on September 7th, 2020. Italy: Istituto Superiore di Sanit;2020.

13. Cordero A, Santos García-Gallego C, Bertomeu-González $\mathrm{V}$ et al. Mortality associated with cardiovascular disease in patients with COVID-19. Rec. Cardioclinics. 2021 JanuaryMarch;56(1):30-8. Epub 2020 Oct 26. PMCID: PMC7587172. https://doi.org/10.1016/j.rccl.2020.10.005

14. Liu K, Fang YY, Deng Y, et al .Clinical characteristics of novel coronavirus cases in tertiary hospitals in Hubei province. Chin Med J (Engl) 2020;133:1025-1031. https://doi.org/10.1097/CM9.0000000000000744

15. Wu Z, McGoogan JM. Characteristics of and important lessons from the coronavirus disease 2019 (COVID-19) outbreak in China: summary of a report of 72314 cases from the Chinese center for disease control and prevention. JAMA. 2020;323:1239-1242. https://doi.org/10.1001/jama.2020.2648

16. Guan WJ, Ni ZY, Hu Y, et al. Clinical characteristics of coronavirus disease 2019 in China. N Eng JMed 2020;382:1708-1720 https://doi.org/10.1056/NEJMoa2002032

17. Asghar MS, HaiderKazmi SJ, Ahmed Khan N et al. Clinical Profiles, Characteristics, and Outcomes of the First 100 Admitted COVID-19 Patients in Pakistan: A Single-Center Retrospective Study in a Tertiary Care Hospital of Karachi. Cureus. 2020 Jun 20;12(6):e8712.

https://doi.org/10.7759/cureus.c34 